九州大学学術情報リポジトリ

Kyushu University Institutional Repository

\title{
Application of Esterase and Peroxidase Zymograms to Breeding in Brassica with Reference to Nucleus Substitution
}

Kanazawa, Ko j i

Laboratory of Horticulture, Faculty of Agriculture, Kyushu University

Eguchi, Hiromi

Biotron Institute, Kyushu University

Iwasa, Shoichi

Laboratory of Horticulture, Faculty of Agriculture, Kyushu University

Uemoto, Shunpei

Laboratory of Horticulture, Faculty of Agriculture, Kyushu University

https://doi.org/10.5109/23717

出版情報 : 九州大学大学院農学研究院紀要. 25 (1)，pp. 25-31，1980-08. Kyushu University バージョン：

権利関係 : 


\title{
Application of Esterase and Peroxidase Zymograms to Breeding in Brassica with Reference to Nucleus Substitution
}

\author{
Koji Kanazawa, Hiromi Eguchi*, Shoichi Iwasa ${ }^{\dagger}$ and Shunpei Uemoto \\ Laboratory of Horticulture, Faculty of Agriculture, \\ Kyushu University 46-01, Fukuoka 812 \\ * Biotron Institute, Kyushu University 12, Fukuoka 812 \\ (Received February 4, 1980)
}

\begin{abstract}
Zymograms of leaf esterases and peroxidases were employed for the use of genetic examination in individual selection to promote nucleus substitution for breeding of new varieties, such as oleracea-cytoplasmic Brassica campestris. In successive strains derived from hybridization of $B$. oleracea $x B$. campestris and backcrosses with pollen of ssp. pekinensis, two of the esterases and one of the peroxidases were found to be specific to $c$ genome. The pattern of the enzyme distribution was characterized by these enzymes, and there were two types of the plants in successive backcrossed strains; one had these enzymes specific to c genome, the other had none of them. Frequencies of the plants having the $c$ genome-specific enzymes became lower according to a decrease in the number of chromosomes of c genome, in process of backcrosses with pollen of ssp. pekinensis. From this result, it was estimated that the chromosomes of c genome can be minimized by selecting the plant having none of the enzymes specific to c genome. and this method is useful for breeding of nucleus-substituted strains in Brassica.
\end{abstract}

\section{INTRODUCTION}

Nucleus substitution is known to be effective for breeding of new varieties, such as oleracea-cytoplasmic Brassica campestris which is used as a cultivar of Chinese cabbage with disease resistances (Nishi et al., 1970). In procedure of the nucleus substitution, an adequate method of genetic examination for individual selection in successive backcrossed strains is needed. The genetic examinations have been performed by analyses of enzymes, since it was made clear that a gene is responsible for formation of an enzyme structure, and the zymogram (Hunter and Markert, 1957) has been used as a powerful tool in genetics (Ogita, 1962; Wright, 1963) and phylogenesis (Eguchi and Matsui, 1969a, b). Present paper deals with comparative analyses of leaf esterases and peroxidases in the zymogram, aiming at developing a new method of individual selection to promote the nucleus substitution in Brassica.

\section{MATERIALS AND METHODS}

Species and strains used in this experiment are listed in Table 1. Brassica

t Present address: Faculty of Agriculture, Iwate University, Morioka 020. 
napus used was derived from artificial synthesis by hybrid of B. oleracea var. capitatax B. campestris ssp. pekinensis and maintained in pedigree culture. Respective strains were obtained by backcrosses with pollen of ssp. pekinensis as described in Table 1 , and their backcross generations were denoted as $B_{1}, B_{2}$ and $\mathrm{B}$, . The chromosomes in the strains were observed in pollen mother cells. The strain in $B_{1}$ comprised $c$ genome (9 of the chromosomes derived from $B$. oleracea). In $B_{2}$, the number of chromosomes of $c$ genome was less than 9. The plants in $B_{3}$ were divided into two strains according to the number of chromosomes of $\mathrm{c}$ genome. Thus, four strains having the different number of chromosomes of $\mathrm{c}$ genome were obtained by means of cytological observation, and their compositions of genome and chromosomes were denoted as $a a c, a a+\alpha, a a+\beta$ and $a a+\gamma$ in the respective strains, where $\alpha \leqq 9, \beta \leqq 5$ and $r \leqq 1$ of the chromosomes of c genome.

Table 1. Explanation of material plants.

\begin{tabular}{|c|c|c|c|}
\hline $\begin{array}{l}\text { Species and strains in } \\
\text { backcross generations }\end{array}$ & Crossing system & Genome & $\begin{array}{l}\text { Number of } \\
\text { plants used }\end{array}$ \\
\hline B. canapestris ssp.pekinensis & - & $a a$ & 10 \\
\hline$B$. oleracea var. capitata & & $\mathrm{cc}$ & 10 \\
\hline $\mathrm{B}_{1}$ & B. napus ${ }^{*} \times$ B. campestris & $a a c$ & 10 \\
\hline $\mathrm{B}_{2}$ & $\mathrm{~B}_{1} \times B$. campestris & $a a+\alpha^{* *}$ & 11 \\
\hline $\mathrm{B}_{3}$ & $\mathrm{~B}_{2} \times B$. canapestris & $\left\{\begin{array}{l}a a+\beta^{* *} \\
a a+\gamma * *\end{array}\right.$ & $\begin{array}{l}4 \\
6\end{array}$ \\
\hline
\end{tabular}

N.B. * Artificially synthesized by hybrid of B. oleracea var. capitatax B. campestris ssp. pekinensis.

* Chromosomes of c genome: $\alpha \leqq 9, \beta \leqq 5$ and $r \leqq 1$.

Five grams of the 7th to 13th leaves of each plant was homogenized with

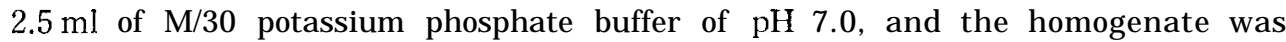
centrifuged at $150,000 \times \mathrm{g}$ for $2 \mathrm{hr}$ to remove cell debris and particles. The supernatant was used as an enzyme solution for zymograms of esterases and peroxidases in agar-gel zone electrophoresis. The gel medium was prepared with $0.7 \mathrm{gm}$ of agar and $4.0 \mathrm{gm}$ of polyvinyl-pyrrolidone in $100 \mathrm{ml}$ of M/30 potassium phosphate buffer of $\mathrm{pH} 7.0$. The gel plate was made $1 \mathrm{~mm}$ thick and supported by a glass plate. A strip of filter paper $(2 \mathrm{x} 12.5 \mathrm{~mm})$ was saturated with the enzyme solution and was placed on the gel plate; the enzyme solution diffused from the filter paper into the agar gel at $2^{\circ} \mathrm{C}$, and the filter paper was removed after $40 \mathrm{~min}$. A gel plate was exposed to stabilized voltage of $17 \mathrm{~V} / \mathrm{cm}$ for $140 \mathrm{~min}$ for esterase separation, and another plate was exposed to $18 \mathrm{~V} / \mathrm{cm}$ for $240 \mathrm{~min}$ for peroxidase separation. For histochemical detection of esterases, $1 \%$ solution of $\beta$-naphthyl acetate was sprayed on the surface of the agar gel as a substrate. After incubating the gel plate at $38^{\circ} \mathrm{C}$ for 40 min, naphthanyl diazo blue $B$ was sprayed on the plate as a dye coupler. For histochemical detection of peroxidases, the gel plate was soaked at $25^{\circ} \mathrm{C}$ for 30 min in a solution containing $1 \%$ hydrogen peroxide and $0.05 \%$ o-dianisidine, which were used as substrate and as dye coupler, respectively. In respective zymograms, esterases and peroxidases were separated enough to examine ge- 
netic variation.

\section{RESULTS AND DISCUSSION}

\section{Esterase pattern}

Figure 1 shows a zymogram of esterases in each of the plants of respective species and strains. In $B$. oleracea, 8 bands of esterases were found, which were designated as EI, EII, EIII, EIV, Ec1,EL?, Ec3 and Ec4, corresponding to an array of the bands from cathode to anode. In B. campestris, 8 bands designated as EI, EII, EIII, EIV, Ea1,Ea2,Ea3 and Ea4 were found. The esterase bands of EI, EII, EIII and EIV were very slight and were found to be non-specific to species. The other bands of Ecs in B. oleracea were different in migration rate from the bands of Eas in B. campestris, and the bands of Ecs and Eas were clearly specific to respective species. In the plants in $\mathrm{B}_{1}$ (aac genomes), esterases of EI, EII, EIII, EIV, Ecl,EaI,Ea2, Ea3 and Ec4 were found as listed in Table 2. Thus, in the digenomic plants having aac genomes, the esterase pattern consisted of the bands found in respective ancestor species of $B$. oleracea and $B$. campestris. In backcrossed strains in $B_{2}$ and $B_{3}$, there were two types of the plants; one had Ecl and/or Ec4, the other had none of these bands specific to $\mathrm{c}$ genome. Thus, genetic variation in the esterase

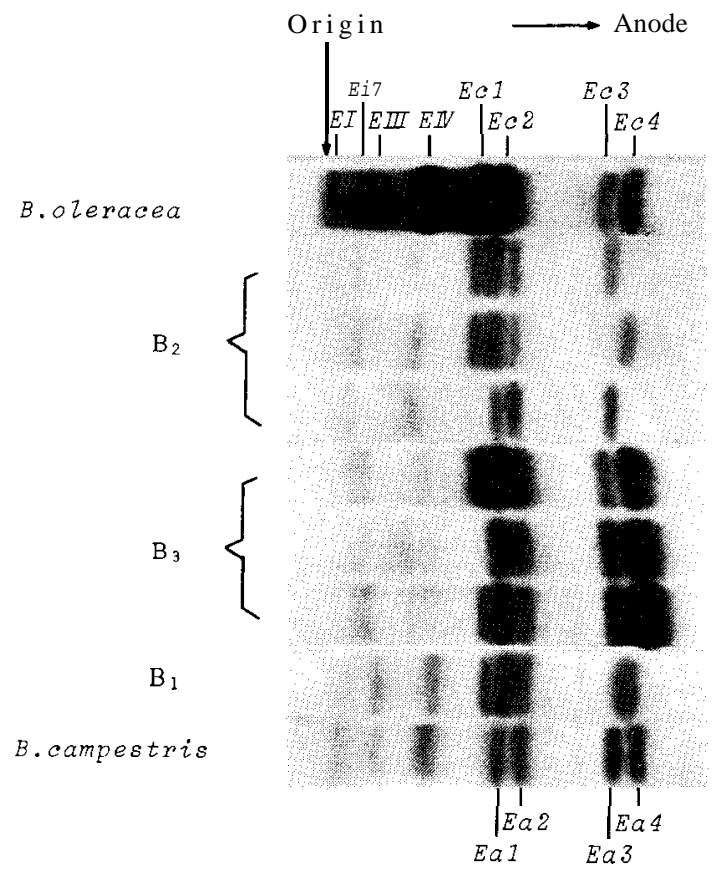

Fig. 1. Photograph of a zymogram of leaf esterases in respective monogenomic species of $a a$ and cc, and successive strains derived from interspecific hybridization and backcrosses with pollen of ssp. pekinensis. 
Table 2. Enzyme compositions in mono- and digenomic species.

\begin{tabular}{|c|c|c|c|}
\hline Plants & Genome & Enzyme & Designated bands in zymogram \\
\hline $\begin{array}{l}\text { B. campestris ssp. } \\
\text { pekinensis }\end{array}$ & $a a$ & $\begin{array}{l}\text { Esterase } \\
\text { Peroxidase }\end{array}$ & 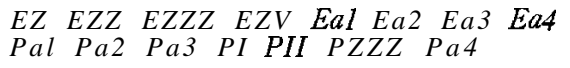 \\
\hline$B_{1}$ & $a a c$ & $\begin{array}{l}\text { Esterase } \\
\text { Peroxidase }\end{array}$ & 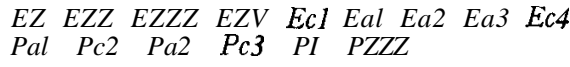 \\
\hline $\begin{array}{l}\text { B. oleracea var. } \\
\text { capitata }\end{array}$ & $c c$ & $\begin{array}{l}\text { Esterase } \\
\text { Peroxidase }\end{array}$ & 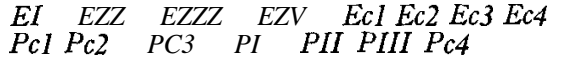 \\
\hline
\end{tabular}

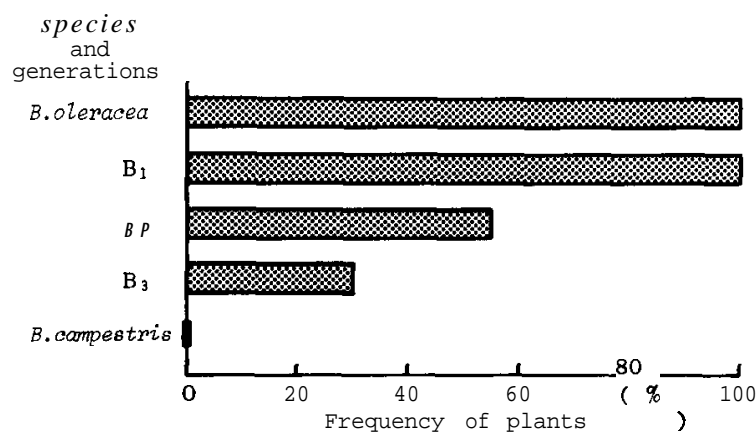

Fig. 2. Frequencies of plants having $E c l$ and/or $E c 4$ on backcross generations.

pattern was characterized by $E c l$ and $E c 4$, and these bands were used as an index for the examination of genetic variation. Figure 2 shows frequencies of the plants having $E c l$ and/or $E c 4$ on generations. These esterase bands

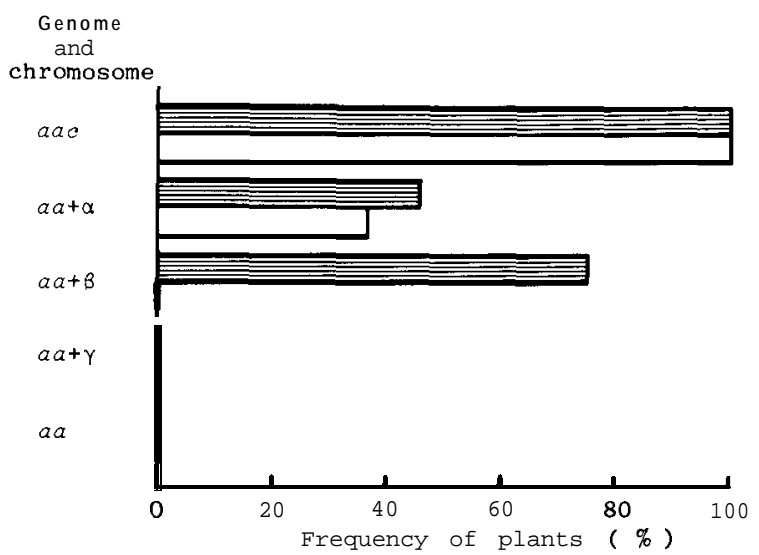

Fig. 3. Frequencies of plants having $E c 1(l)$ and $E c 4(\square)$ on the number of chromosomes of $c$ genome, where $\alpha, \beta$ and $\gamma$ are the number of chromosomes of c genome: $\alpha \leqq 9, \beta \leqq 5$ and $r \leqq 1$. 
were found in all plants in $B_{1}$. These bands were found in $55 \%$ of the plants in $\mathrm{B}_{2}$ and $30 \%$ in $\mathrm{B}_{3}$. Thus, the frequency of the plants having these esterases decreased in backcrosses with pollen of ssp. pekinensis.

Figure 3 shows frequencies of the plants having $E c l$ and those having $E c 4$ in respective strains on the number of chromosomes derived from c genome. As mentioned above, in digenomic strain (aac) having 9 chromosomes of c genome, $E c l$ and Ec4 were found in all plants. In the strain $(a a+\alpha)$ in which the number of chromosomes of c genome was less than $9, E c l$ was found in $46 \%$, and Ec4 was found in $36 \%$ of the plants. In the strain $(a a+\beta)$ having 5 chromosomes of $\mathrm{c}$ genome at its maximum, the percentage of the plants having $E c l$ was $75 \%$, and that of the plants having Ec4 became $0 \%$. In the strain $(a a+r)$ having one or none of the chromosomes of c genome, these esterases were not found. Thus, the frequency of the plants having $E c l$ and/ or Ec4 became lower according to the decrease in the number of chromosomes of c genome derived from $\boldsymbol{B}$. oleracea.

\section{Peroxidase pattern}

Figure 4 shows a zymogram of peroxidases in each of the plants. Peroxidase pattern in $\boldsymbol{B}$. oleracea was composed of 7 bands which were designated as Pcl, Pc2, Pc3, PI, PII, PIII and Pc4, corresponding to an array of the bands

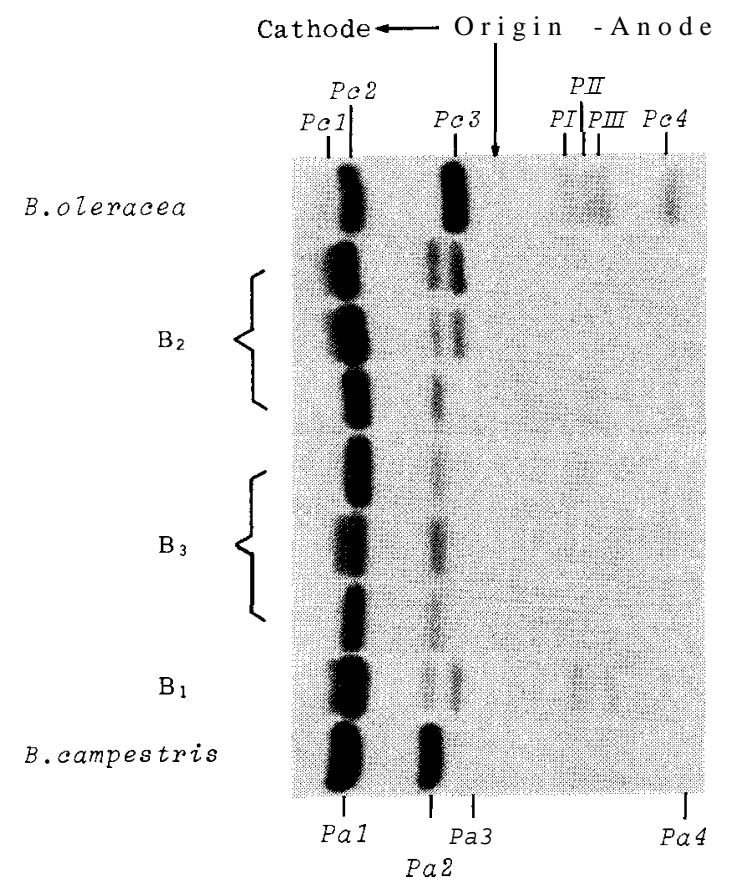

Fig. 4. Photograph of a zymogram of leaf peroxidases in respective monogenomic species of $a a$ and cc, and suscessive strains derived from inter-specific hybridization and backcrosses with pollen of ssp. pekinensis. 
from cathode to anode. In B. campestris, 7 bands designated as Pal, Pa2, Pa3, $P I, P I I, P I I I$ and Pa4 were found. The intensities of PI, PII and PIII were very slight and not species-specific. There were distinct differences in migration rate between $P C$ bands and $P a$ bands. The plants in $\mathrm{B}$, comprised the peroxidases of Pal, Pc2, Pa2,Pc3, PI and PIII bands, as listed in Table 2. Thus, in the digenomic plants ( $a a c$ ) in $\mathrm{B}_{1}$, peroxidase pattern consisted of the bands found in respective ancestor species of $B$. oleracea and $B$. campestris. However, the migration rates of $P c l, P a l$ and $P c 2$ were close to each other, and it was difficult to use those bands as an index for the examination of genetic variation. In $\mathrm{B}_{2}$ and $\mathrm{B}_{3}$, some of the plants had $P c 3$, and others had not this enzyme. The genetic variation in peroxidase pattern was characterized clearly by $P c 3$. So, $P c 3$ was used as an index for the examination of genetic variation. Figure 5 shows frequencies of the plants having $P c 3$ on generations. The Pc3 was found in all plants in $B_{1}$ as mentioned above and found in $55 \%$ of the plants in $B_{2}$. However, Pc3 was not found in $B_{3}$. Thus, the frequency of the plants having $P c 3$ decreased in the process of backcrosses with pollen of ssp. pekinensis.

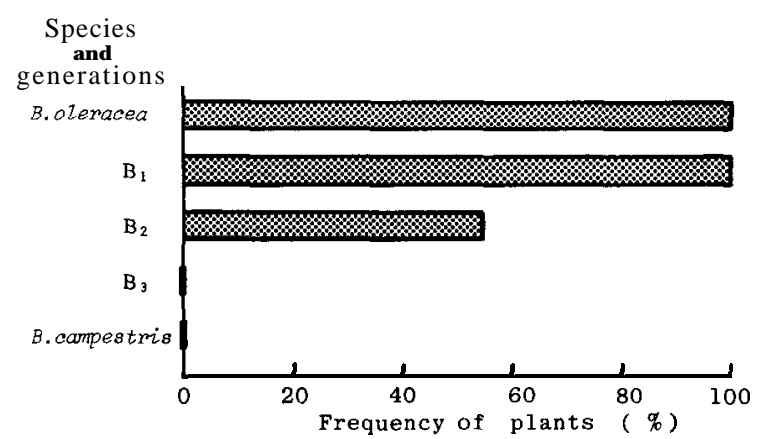

Fig. 5. Frequencies of plants having $P c 3$ on backcross generations.

Figure 6 shows frequencies of the plants having $P c 3$ in respective strains on the number of chromosomes derived from $c$ genome. In digenomic strain (aac), Pc3 was found in all plants as mentioned above. On the other hand, $P c 3$ was found in $55 \%$ of the plants of strain $(a a+\alpha)$ having less than 9 chromosomes of $\mathrm{c}$ genome. In the strain $(a a+\beta)$ having less than 5 chromosomes of $\mathrm{c}$ genome and the strain $(a a+r)$ having one or none of the chromosomes of c genome, $P c 3$ was not found. Thus, the frequency of the plants having PC3 became lower according to the decrease in the number of chromosomes of $c$ genome in the process of backcrosses with pollen of ssp. pekinensis, as well as the genetic variation examinkd in esterases.

\section{Conclusion}

In the successive strains derived from hybridization of $B$. oleracea var. capitata $\times$ B. campestris ssp. pekinensis and backcrosses with pollen of ssp. pekinensis, the number of chromosomes of $\mathrm{c}$ genome derived from $B$. oleracea varied 


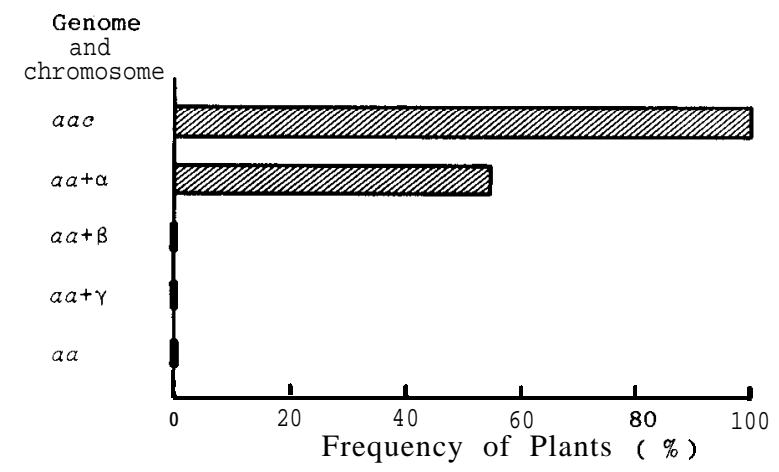

Fig. 6. Frequencies of plants having $P c 3$ on the number of chromosomes of $\mathrm{c}$ genome, where $\alpha, \beta$ and $\gamma$ are the number of chromosomes of c genome: $\alpha \leqq 9, \beta \leqq 5$, and $\gamma \leqq 1$.

with the respective generations (Iwasa, 1963). For promoting nucleus substitution, these chromosomes of $\mathrm{c}$ genome should be removed by individual selection in successive strains. Variations in enzyme pattern in the backcrossed strains related to the number of chromosomes of $c$ genome, and the frequency of the plants having the enzymes specific to $c$ genome became lower in proportion to the decrease in the number of these chromosomes. From this result, it was estimated that the chromosomes of c genome can be minimized by selecting the plant having none of the enzymes specific to c genome, and this method is useful for breeding of nucleus-substituted strains in Brassica.

\section{REFERENCES}

Eguchi, H. and T. Matsui 1969a Relationships between genome constitution and esterase composition in Brassica. J.Fac. Agr., Kyushu Univ., 15: 331-344

Eguchi, H. and T. Matsui 1969b Phylogenetic study on Cucurbita species by means of esterase zymogram. J.Fac. Agr., Kyushu Univ., 15: 345-353

Hunter, R. L. and C. L. Markert 1957 Histochemical demonstration of enzymes separated by zone electrophoresis in starch gels. Science, 125: 1294-1295

Iwasa, S. 1963 Studies on the alloplasmatic effect in tribe Brassiceae. I. On the carinatacytoplasmic Brassica pekinensis induced by the successive back-crosses. J. Fac. Agr., Kyushu Univ., 12: 201-212

Nishi, S., M. Toda, S. Umeda and T. Toyoda 1970 Studies on the breeding of cruciferae vegetables by interspecific and intergeneric hybridization II. Breeding of disease resistant chinese cabbage by backcrossing to interspecific hybrids between cabbage and Chinese cabbage. Bull, Hort. Res. Sta., Japan, Ser. A, 9: 101-128 (in Japanese with English summary)

Ogita, Z. 1962 Genetico-biochemical analysis on the enzyme-activities in the house fly by agar gel electrophoresis. Japan. Jour. Genet., 37: 518-521

Wright, T. R. F. 1963 The genetics of an esterase in Drosophila melanogaster. Genetics, 48: 787-801 